\title{
THE MALE GENITALIA OF BLATTARIA. VIII. PANCHLORA, ANCHOBLATTA, BIOLLEYA, PELLOBLATTA, AND ACHROBLATTA.
}

(BLABERIDAE: PANCHLORINAE).

\author{
By Louis M. Roth
}

Pioneering Research Laboratory

U. S. Army Natick Laboratories

Natick, Massachusetts or 760

McKittrick ( 1964) placed three blaberid genera, Panchlora Burmeister, Achroblatta Saussure, and Capucina Saussure, in the Panchlorinae. Princis (1960) listed Panchlora, Phortioecoides Rehn, and Proscratea Burmeister under the Panchloridae. My studies of male genitalia of Blaberidae have shown that Capucina and Phortioecoides are members of the Zetoborinae (Roth 1970a). The genitalia of Proscratea differ markedly from those of genera I believe should be placed in the Panchlorinae and I do not consider it in this paper.

The male genitalia of species of Panchlora, Achroblatta, Anchoblatta Shelford, Biolleya Saussure, and Pelloblatta Rehn are basically similar and I place these five genera in the Panchlorinae. Unfortunately the male genitalia of an undescribed species of Pelloblatta were lost in preparation, due principally to their marked reduction and light sclerotization. Princis (1965) placed Pelloblatta in the Oxyhaloidae but the male genitalia of members belonging to the Oxyhaloinae (Roth, I97I) differ markedly from those of the Panchlorinae. Princis (1960) placed Achroblatta in the Laxtinae, a subfamily which he considered provisional (Roth, I970a), and Biolleya in the Latindiidae. McKittrick (1964) placed Laxta in the Epilamprinae, tribe Laxtini. The genus Latindia Stål is an oviparous polyphagid genus whereas Biolleya is an ovoviviparous member of the Blaberidae. Princis ( 1960) placed Anchoblatta in the Brachycolinae with a (?) but included it under this subfamily in his 1963 Catalogus. I consider Princis' Brachycolinae to be a tribe in the Blaberinae (Roth, 1970b). Anchoblatta signifera (Scudder) was originally placed in Panchlora, but Kirby assigned it to Achroblatta. Princis (1963) listed Anchoblatta signifera with a query under Achroblatta, but Gurney (personal communication) regards it to be an Anchoblatta.

\section{Materials AND Methods}

The genitalia were treated with $10 \% \mathrm{KOH}$ and mounted in Permount. Considerable care must be taken with these specimens because they are so lightly sclerotized and small that they can be readily 


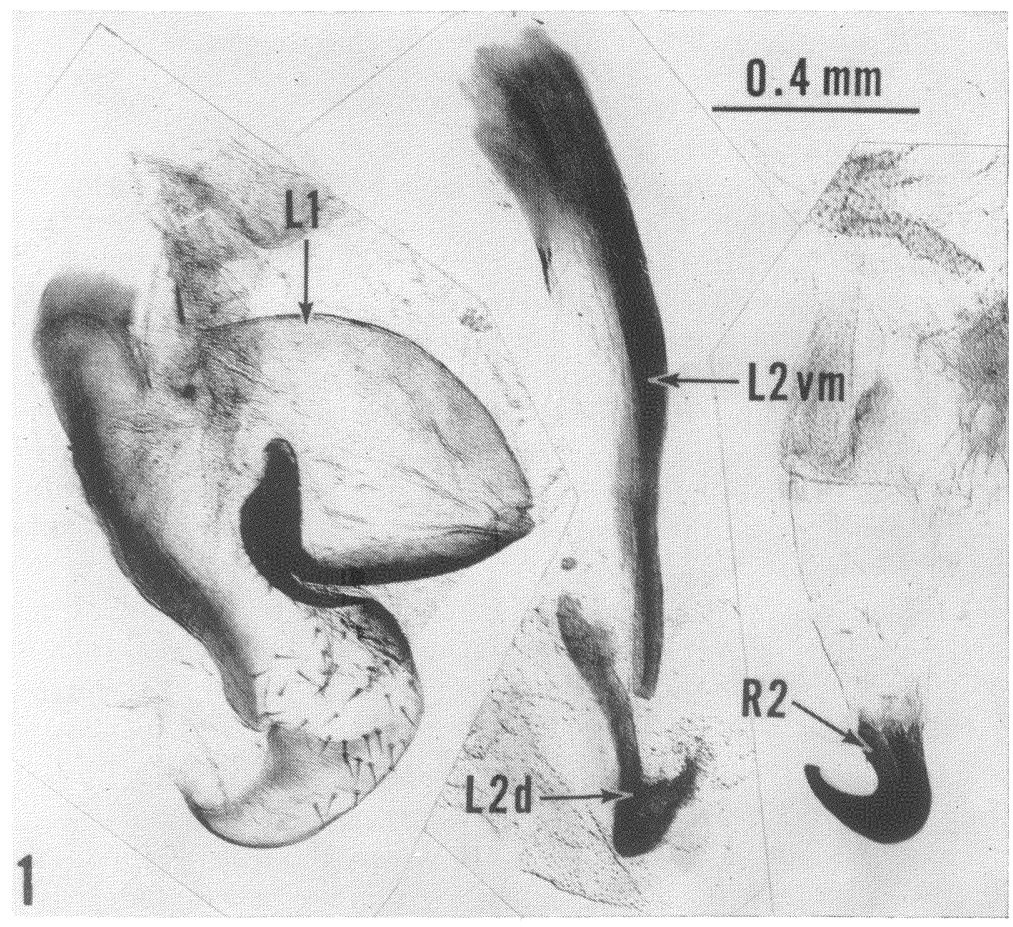

Fig. 1. (978 L). Male genitalia (dorsal view) of Panchlora vosseleri Shelford. Usambara-Berg, Tanganyika (det. Princis). $(\mathbf{L} 1=$ first sclerite of left phallomere; L2d $=$ dorsal sclerite of $\mathrm{L} 2$; L2vm $=$ ventromedial sclerite; R2 = hooked sclerite of right phallomere. To conserve space the photographs of the phallomeres have been placed closer together than they were arranged on the slide.

lost in preparation. Because of light pigmentation, Polaroid Type $5 \mathrm{I}$, high-contrast film usually was used to illustrate them (cf. Figs. 2I-22).

The source of each of the specimens illustrated is given using the following abbreviations: $(\mathrm{BMNH})=$ British Museum (Natural History), London; (CUZM) = Copenhagen University, Zoological Museum, Denmark; $(\mathrm{L})=$ Zoological Institute, Lund, Sweden; $(\mathrm{N})=$ U. S. Army Natick Labs.; (USNM) = United States National Museum, Washington, D.C. Geographical collection data and the names of specialists who identified the specimens, if known, follow these abbreviations. The number preceding the abbreviations 
refers to the number assigned the specimen and its corresponding genitalia (on a slide) which are deposited in their respective museums.

\section{Results and Discussion}

The most characteristic feature of the male genitalia of most Panchlorinae is the absence of the genital hook and light pigmentation and marked reduction of the remaining 2 phallomeres when they are present. McKittrick (1964, p. 72) noted the marked reduction in the genitalia of Panchlora nivea and pointed out that the only sclerotized structures are the cleft region of $\mathrm{L}_{\mathrm{I}}$ and the lightly pigmented median sclerite (L2vm). However, a study of several species of Panchlora shows that some forms have all three phallomeres (Figs. I-4); males that lack certain phallomeres probably evolved from species that had them. Based upon the presence or absence of genital phallomeres, the Panchlora studied here can be divided into the following Species Groups:

Group I (Panchlora vosseleri). Though lightly sclerotized, all three basic phallomeres are present, including an L2d (Figs. I-4).

Group 2 (Panchlora stanleyana). L2d is absent; Lr, L2vm, and $\mathrm{R}_{2}$ are present (Figs. 5-7).

Group 3 (Panchlora nivea, P. thalassina). L2d and R2 are absent; LI, and L2vm, are present (Figs. 8-15).

Group 4 (Panchlora bidentula, P. minor, P. sagax, P. dumicola, $P$. peruana). L2d, $\mathrm{R}_{2}$, and apparently $\mathrm{L}_{2} \mathrm{vm}$ are absent; only $\mathrm{L}_{\mathrm{I}}$ is present (Figs. I6-20).

Group 5 (Panchlora exoleta Burmeister). Apparently no sclerotized structures are present.

Groups I and 2 are African and 3 to 5 are found in Central and/ or South America.

In Groups 4 and 5 it is quite possible that L2vm was so lightly sclerotized and $\mathrm{L}_{\mathrm{I}}$ so small, and poorly defined, that they were lost in preparation of the genitalia.

The male phallomeres L2vm of Achroblatta (Figs. 24-25), Biolleya (Figs. 21-23), and Anchoblatta (Figs. 26-29) are very lightly pigmented. $\mathrm{L}_{\mathrm{I}}$ is also reduced as in most Panchlora, and L2d and R2 are absent.

The marked reduction in the male genital phallomeres of this subfamily may be related, in some way, to the mating behavior of these genera. In most species of cockroaches the receptive females respond to male courtship by palpating his dorsum, which in many genera possesses specialized glands which persumably produce a secretion at- 


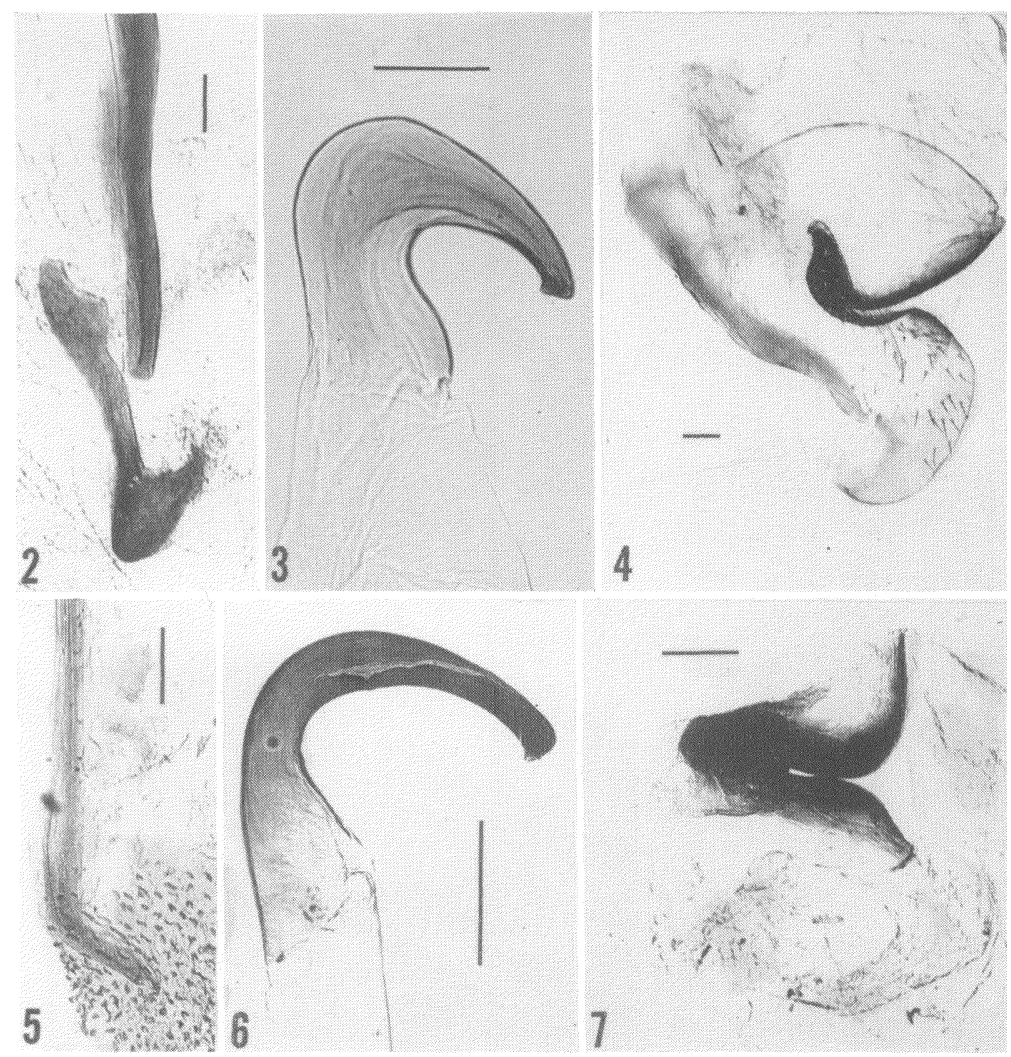

Figs. 2-7. Male genitalia of Panchlora spp. 2-4. (978 L). P. vosseleri (same specimen as shown in Fig. 1). 5-7. P. stanleyana Rehn. 5-6. (977 L) Cameroon Republic (det. Princis). 7. (N). Ivory Coast (det. Roth). (scale= $0.1 \mathrm{~mm})$. 


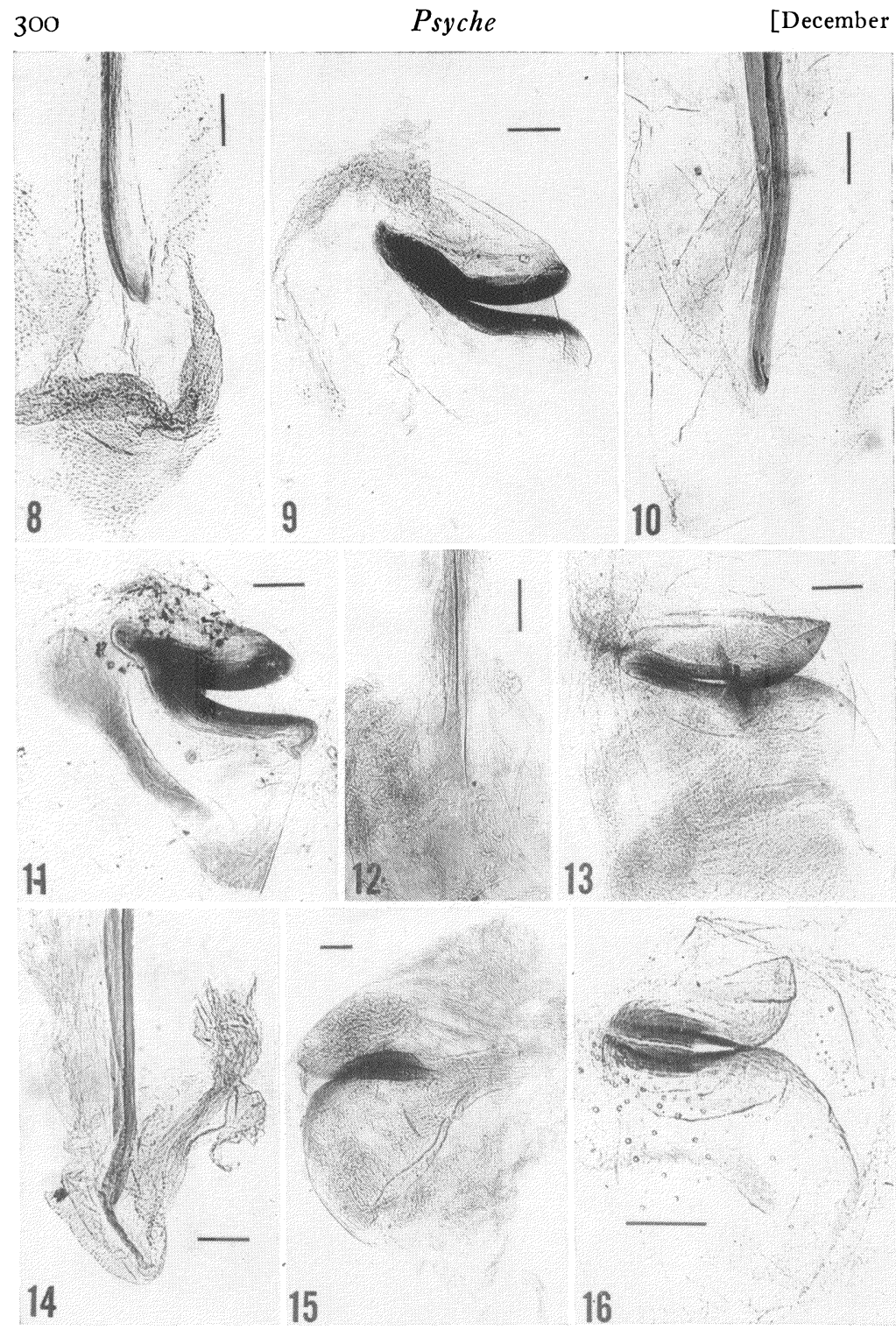

Figs. 8-16. Male genitalia of Panchlora spp. 8-9. (N). P. nivea (det. Gurney). 10-11. (56 BMNH). P. thalassina Saussure and Zehntner. Villa Ana, F.C.S.F. Argentina (det. Hebard). 12-13. (173 USNM). P. sp. Palenque, Chiapas, Mexico. 14-15. (172 USNM). P. sp. Palenque, Chiapas, Mexico. (15 is a ventral view). 16. (57 $\mathrm{BMNH})$. P. bidentula Hebard. Mosqueiro, Rio de Para (det. Hebard). (scale $=0.1 \mathrm{~mm})$. 

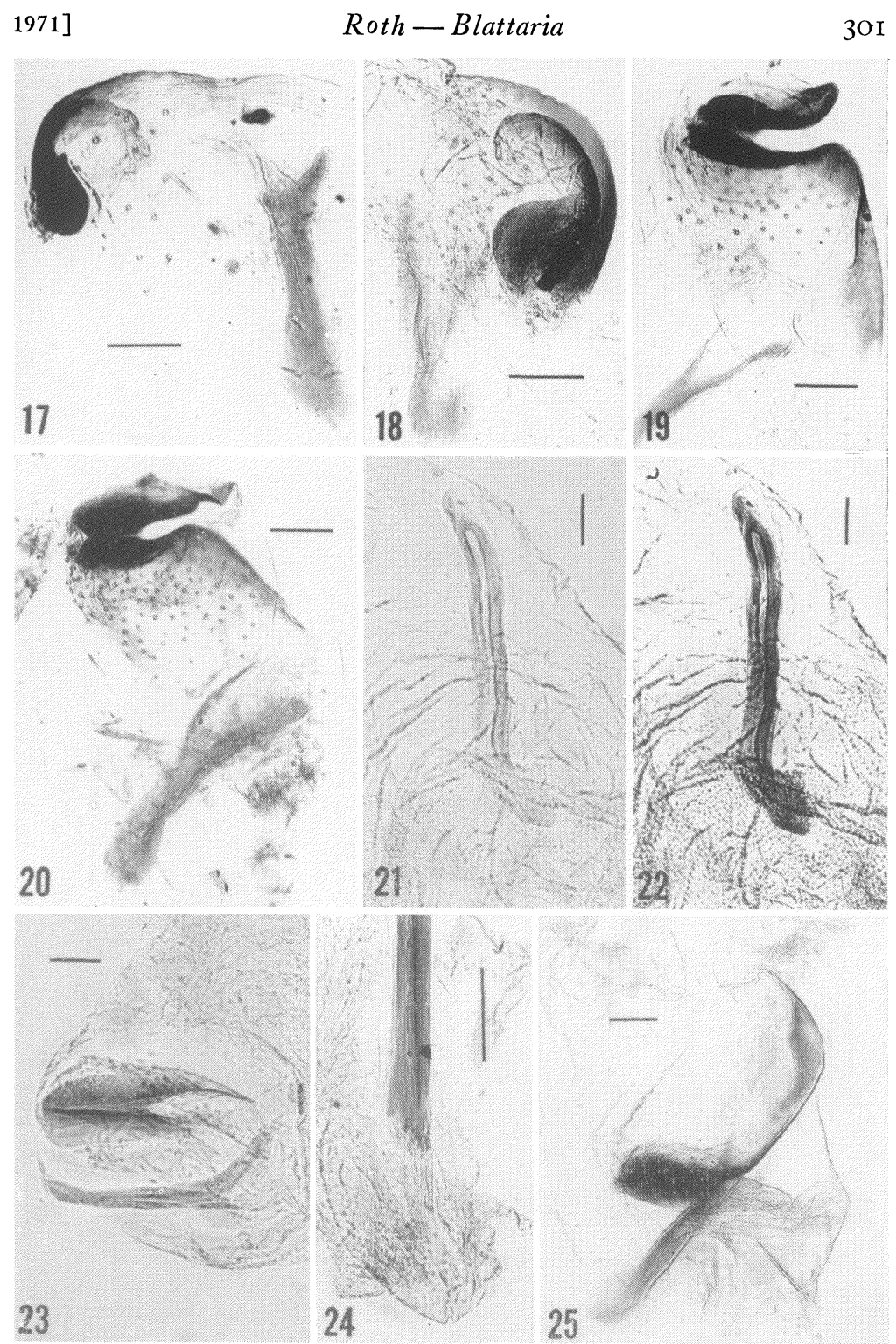

Figs. 17-25. Male genitalia of Panchlorinae. 17. (976 L). Panchlora peruana Saussure. Bolivar, Batatal, Colombia (det. Princis). 18. (57 CUZM). Panchlora minor Saussure and Zehntner. Brazil (det. Princis). 19. (973 L). Panchlora sagax Rehn and Hebard. St. Thomas, Lesser Antilles (det. Princis). 20. (975 L). Panchlora dumicola Albuquerque and Gurney. Brazil (det. Princis). 21-23. (174 USNM). Biolleya alaris Saussure. Paratype. La Palma, Costa Rica. (Figs. 21 and 22 are the same L2vm taken with Polaroid Type 51 and 52 film respectively). 24-25. Achroblatta luteola (Blanchard). Darien Province, Sante Fe, Panama (det. Fisk). $($ scale $=0.1 \mathrm{~mm})$. 


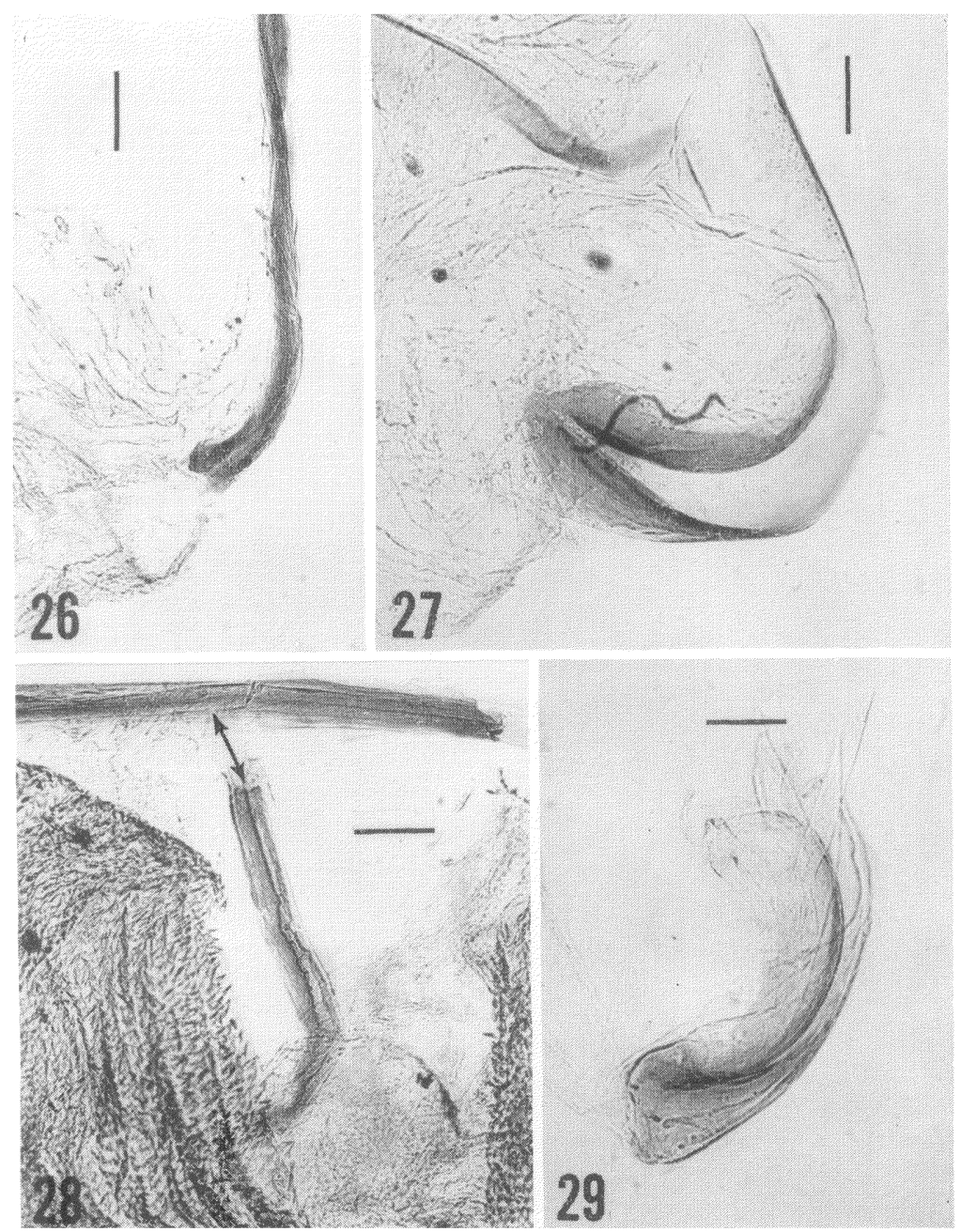

Figs. 26-29. Male genitalia of Anchoblatta. 26-27. (170 USNM). Signifera (Scudder). San Martin, Peru (det. Gurney). 28-29. (53 USNM). Rio Ucuyali, Pucallpa, Peru (det. Gurney). (L2vm was accidentally broken [arrows indicate the two parts of the sclerite]). (scale $=0.1 \mathrm{~mm})$. 
tractive to the female (Roth, I969). When the female is in the proper position above the male he extends the genital hook ( R2) and seems to use this structure to pull down the female's subgenital plate so that he can insert his genitalia and grasp her genitalia. According to Khalifa (1958) in Blattella germanica (L.), when the female is palpating the male's tergal glands, the male fully extends the hooked phallomere, which is on the left side in this genus (not the right as in all Blaberidae) directs it upwards, and inserts it into the female's genital chamber; there it clasps a sclerite situated in front of the ovipositor. Once a secure hold is obtained, the pair assumes an end-to-end position, with their heads facing in opposite directions, and the hook ". . . acquires a hold on the ovipositor." In Periplaneta americana (L.) the male ". . . prior to getting an actual hold on the female pulls down the gynovalvular portion of the seventh sternite of the female by the tip of its protruded titillator." and then inserts its genitalia into the female's genital pouch. (Gupta, I947). Zabinski (I933) showed that the titillator, in Blatta orientalis, is used to seize the female in the initial phase of copulation. The male apparently cannot mate if the titillator (genital hook or $\mathrm{R}_{2}$ in Blaberidae) is surgically removed (Zabinski, I933, Roth and Willis, I952).

The mating behavior of Panchlora differs markedly from the above species. In Panchlora nivea (Roth and Willis, I958) and P. irrorata Hebard (Willis, I966) the female does not assume a position above the male prior to mating, but the males simply back into the female. Possibly stridulation plays a role in mating behavior of these species (Roth and Hartman, 1967). The difference in precopulatory positions may have had some role in the marked reduction of male genitalic structures, especially the loss of the genital hook. Nothing is known of the precopulatory positions of the genera of Achroblatta, Anchoblatta, and Biolleya, and it would be of interest to see if the mating behavior of these genera is similar to that of Panchlora. It should be pointed out that in Gromphadorhina portentosa (Schaum) (Oxyhaloinae) the male also backs into the female to assume the copulatory position (Barth, I968) but the males of this genus have a well-developed, but relatively short, genital hook (Roth, I97I).

\section{Summary}

Five genera, Panchlora, Anchoblatta, Biolleya, Pelloblatta, and Achroblatta are included in the blaberid subfamily Panchlorinae. Certain male genitalic phallomeres are usually reduced or absent and structures that are present are very lightly sclerotized. One African 
species of Panchlora has all the phallomeres characteristic of most male blaberid genitalia. Five groups are erected for species of Panchlora, based on the number of phallomeres which are missing. 'The genital hooks ( $\mathrm{R}_{2}$ ) are absent in Panchlora (from Central and/ or South America), Achroblatta, Biolleya, and Anchoblatta.

The mating behavior of Panchlora differs from most other Blattaria, and it is discussed in relation to the loss of the genital hook.

\section{ACKNowledgments}

I thank the following for the loan of museum specimens: Dr. David Ragge (British Museum), Dr. Ashley Gurney (U. S. National Museum), Dr. Karl Princis (Lund), Dr. S. L. Tuxen (Copenhagen), and Dr. Frank Fisk. I am grateful to Mr. Samuel Cohen for taking the photographs.

BARTH, R. JR.

\section{REFERENCES}

1968. The mating behavior of Gromphadorhina portentosa (Schaum) (Blattaria, Blaberoidea, Blaberidae, Oxyhaloinae) : an anomalous pattern for a cockroach. Psyche 75: 124-131.

Gupta, P. D.

1947. On copulation and insemination in the cockroach Periplaneta americana (Linn.). Proc. Nat. Inst. Sci. India 13: 65-71.

Khalifa, A.

1950. Spermatophore production in Blattella germanica L. Orthoptera: Blattidae). Proc. Roy. Entomol. Soc. London 25(A) : 53-61.

McKitTrick, F. A.

1964. Evolutionary studies of cockroaches. Cornell Univ. Agr. Exp. Sta. Mem. No. 389, 197 pp.

\section{Princis, K.}

1960. Zur systematik der Blattarien. Eos 36: 427-449.

1963. Orthopterorum Catalogus. Subordo Polyphagoidea: Fam. Homoeogamiidae, Euthyrrhaphidae, Latindiidae, Anacompsidae, Atticolidae, Attaphilidae. Subordo Blaberoidea: Fam. Blaberidae. s'-Gravenhage, pp. 76-172.

RоTн, L. M.

1969. The evolution of male tergal glands in the Blattaria. Ann. Entomol. Soc. Amer. 62: 176-208.

1970a. The male genitalia of Blattaria. III. Blaberidae: Zetoborinae. Psyche 77: 217-236.

1970b. The male genitalia of Blattaria. IV. Blaberidae: Blaberinae. Psyche 77: 308-342.

1971. The male genitalia of Blattaria. VI. Blaberidae: Oxyhaloinae. Psyche 78: 84-106.

Roth, L. M. and H. B. Hartman.

1967. Sound production and its evolutionary significance in the Blattaria. Ann. Entomol. Soc. Amer. 60: 740-752. 
Roth, L. M. AND E. R. Willis.

1952. A study of cockroach behavior. Amer. Midland Nat. 47: 66-129.

1958. The biology of Panchlora nivea with observations on the eggs of other Blattaria. Trans. Amer. Entomol. Soc. 83. 195-207.

WILLIS, E. R.

1966. Biology and behavior of Panchlora irrorata, a cockroach adventive on bananas. Ann. Entomol. Soc. Amer. 59: 514-516.

ZABINSKI, J.

1933. Fonctionnement des différentes parties des appareils copulateurs chitinés males et femelles de la Blatte (Periplaneta orientalis L.). Soc. de Biol. de Varsorvie 112: 598-602. 

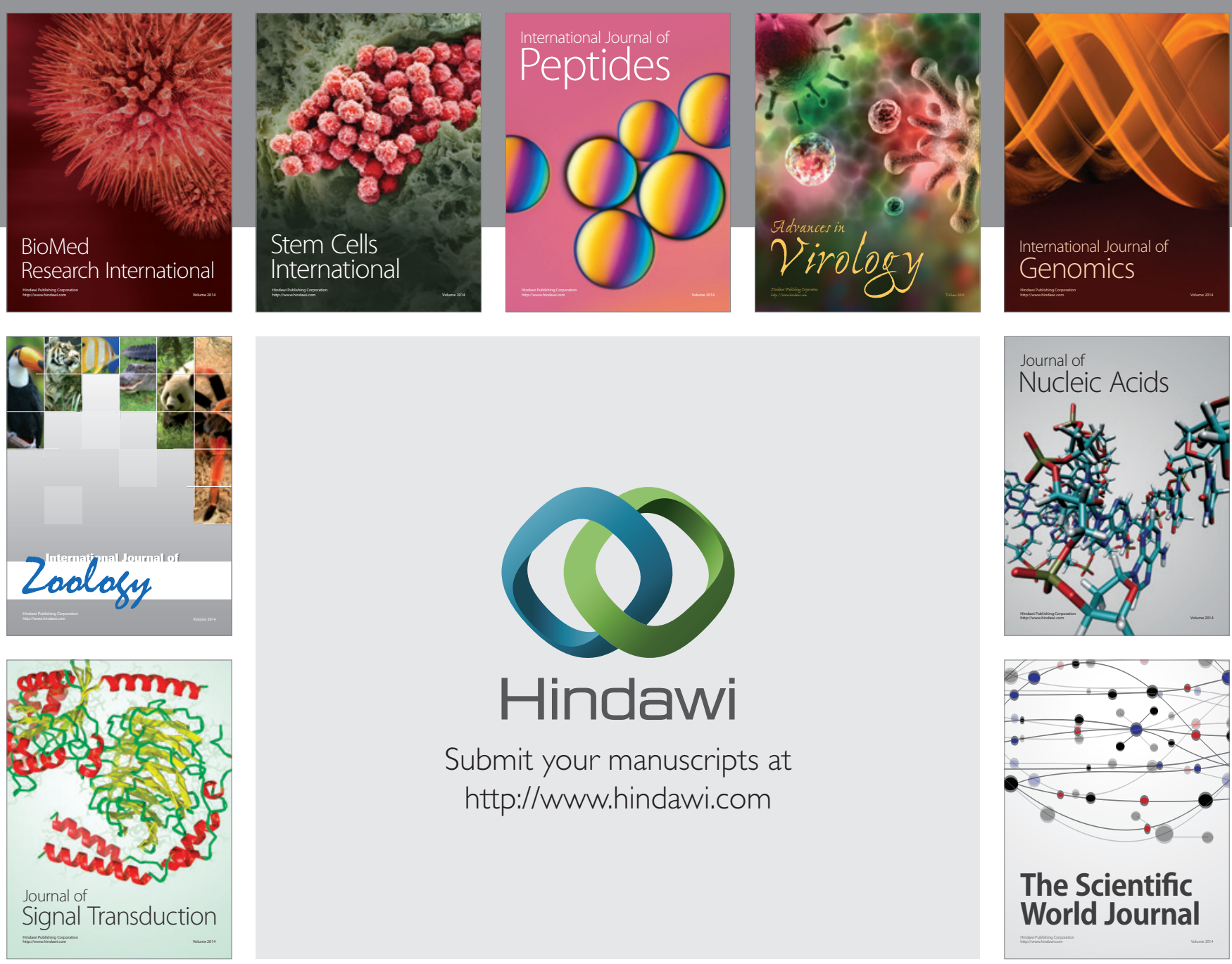

Submit your manuscripts at

http://www.hindawi.com
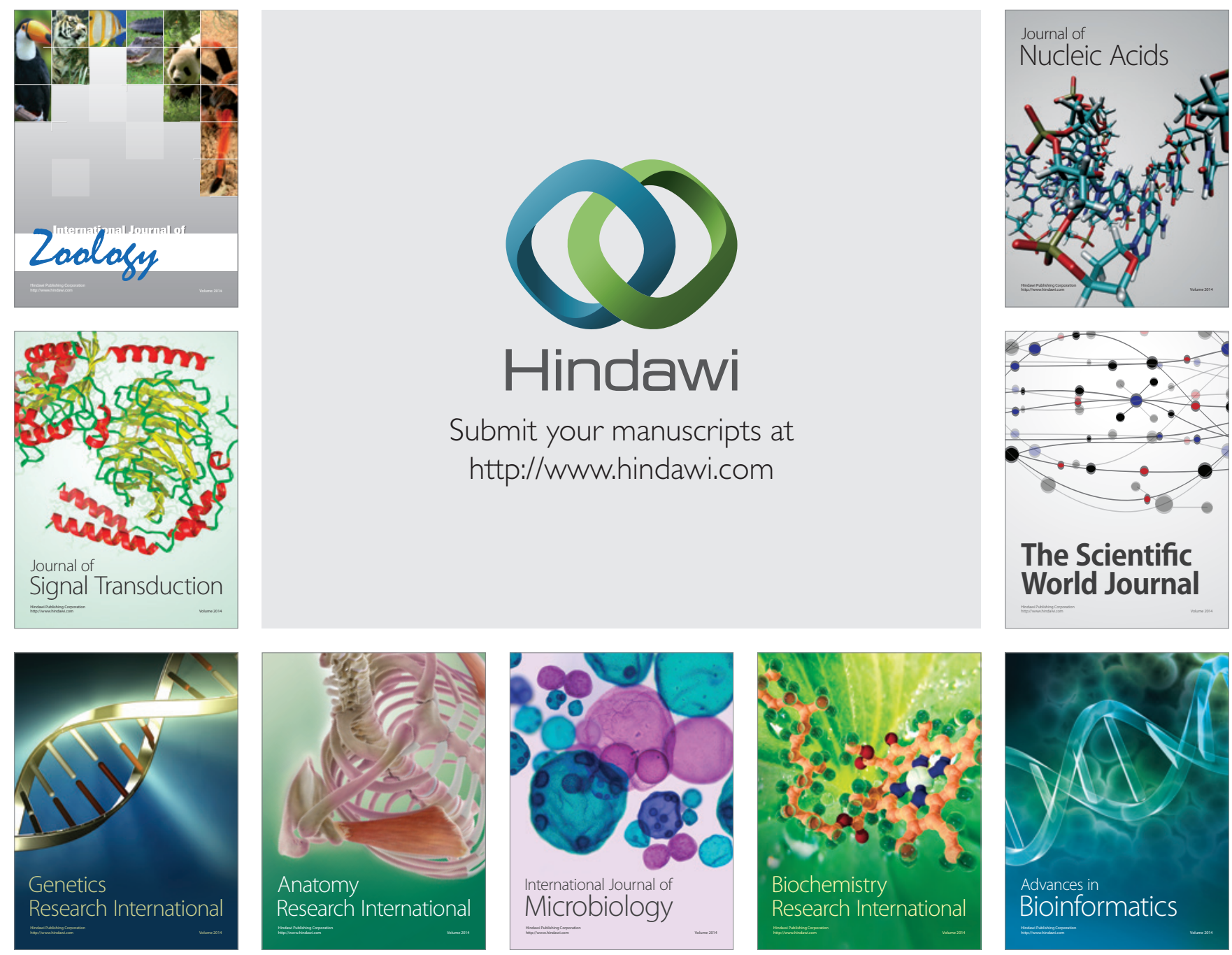

The Scientific World Journal
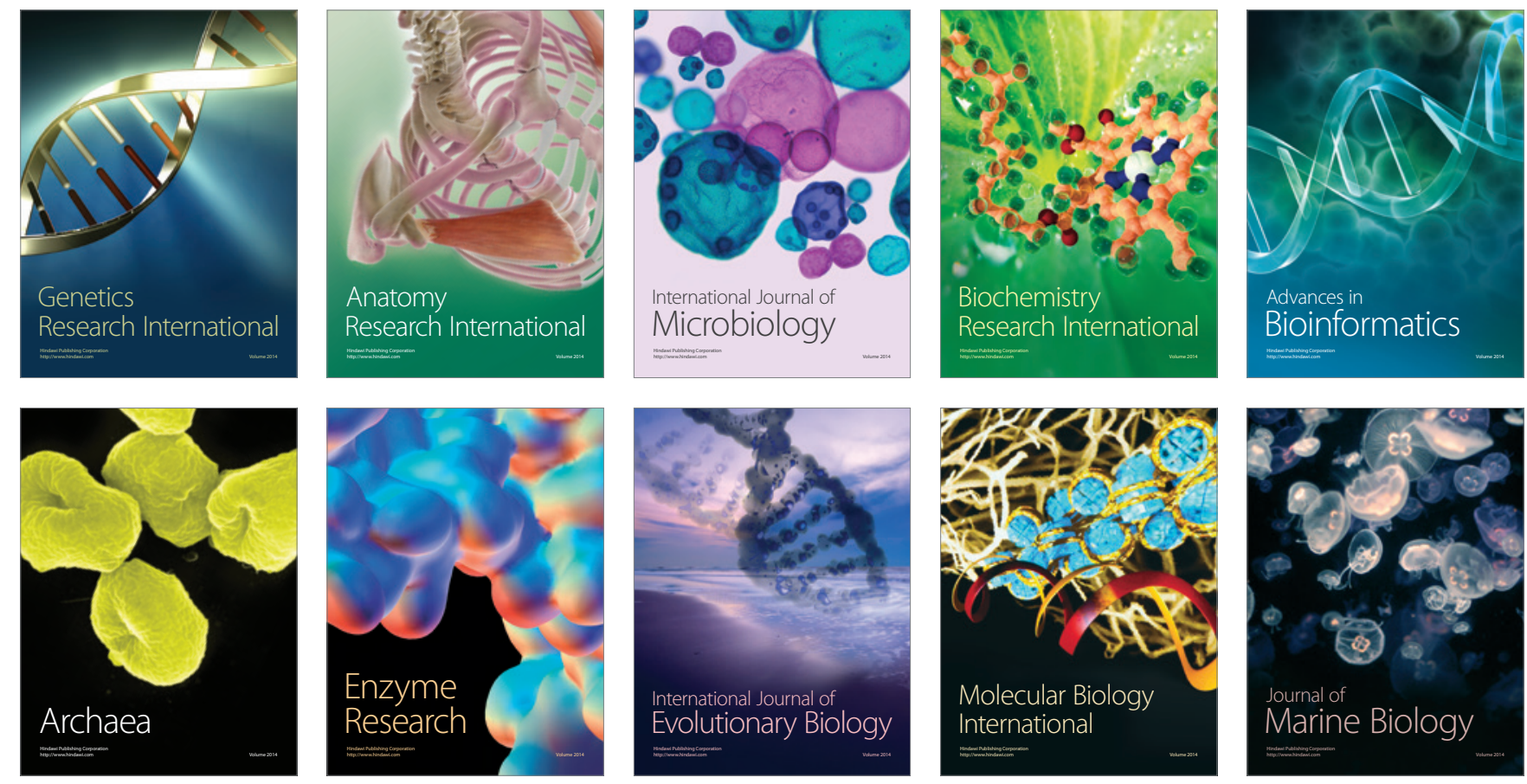